\title{
Time of day and the EEG: Some negative results $* * * *$
}

\author{
ANTHONY GALE $\uparrow$, BRIAN HARPHAM, and BONNIE LUCAS \\ Washington Singer Laboratories, University of Exeter \\ Exeter EX4 4QC, England
}

Twenty Ss each attended, on four occasions at four times of day, on a randem schedule. The times of day were $0700,1100,1500$, and $2000 \mathrm{~h}$. The resting EEG was recorded on each occasion during eyes-open and eyes-closed trials. The results were: (1) there were no general effects for the time of day nor any indication of an interaction between time of day and personality (extroversion-introversion and neuroticism); (2) the Ss maintained rank order for alpha abundance, within the group, over the four visits $(p<.01)$; (3) extroversion was directly related to degree of variability across sessions ( $\mathrm{p}<.05)$; and (4) alpha abundance was greater on the first visit than on the last visit $(p<.05)$. These results demonstrate the within-S stability of the EEG and show that, for simple tasks of this nature, time of day has no effect on the EEG.

Evidence from several sources indicates that time of day (TOD) influences a number of dependent variables. Effects have been demonstrated for simple sorting tasks (Kleitman, 1933), temperature (Blake, 1965), and vigilance performance (Colquhoun \& Corcoran, 1964). Moreover, TOD has been shown to have a differential effect upon different personality groups; extroverts are said to be at a peak of alertness in the afternoon and introverts at a peak in the morning (Colquhoun, 1960). The psychological data relating to such diurnal variation has been drawn together within an arousal theory framework (Davies \& Tune, 1970). Thus, variation in arousal or activation, which in itself is a function of as yet unidentified physiological variations, is a determinant of level of performance.

The EEG has been shown to be an acceptabie operational measure of arousal level and is the key dependent variable in Lindsley's classical statement of activation theory (1960). In studies with animals, the EEG has been the most popular electrophysiological index of the vigilance of the central nervous system. In human studies, the EEG has been employed successfully to differentiate between levels of sleep, complexity of stimuli, fluctuations in reported alertness, criterion personality groups, and so on (e.g., Oswald, 1962; Gale, Christie, \&

*This work was supported by a grant from the Medical Research Council to the first author (reference G. 969/185C).

**The authors wish to thank the Commanding Officer, Wessex Depot, Prince of Wales Division, Exeter, for provision of experimental Ss for this study.

tAnthony Gale is now at the Department of Psychology, University College, Swansea SA 2 8PP.
Penfold, 1971; Gale, Haslum, \& Penfold, 1971; Gale, Coles, \& Blaydon, 1969).

The present study was designed to measure the effect of TOD (and, thus, diurnal variation in arousal) upon the human EEG. Studies of this nature present interesting problems of design, and a number of alternative strategies are available. First, large groups may be used, different individuals being tested at different times of day; but, to avoid sampling error and error variance attributable to individual differences, such groups must be so large as to generate unmanageable quantities of data. A second alternative is a repeated-measures design, in which the same individual attends at a sequence of times throughout the same day. Although such a design provides optimal control (since each $\mathrm{S}$ is his own control), general adaptation effects are confounded with TOD effects, such that a trend over TOD may be merely a function of number of visits to the l a boratory. The ideal repeated-measures design involves sequential visits of $\mathrm{Ss}$ with staggering of time of first attendance, so that TOD and adaptation effects may be discriminated. However, such a design calls for considerable ingenuity in programming of $S$ attendance. The fourth alternative, which is employed in the present study, is repeated measures, with random attendance at the times of day, over a brief period of days. Over and above the difficulty of design, there is the problem of $S$ volunteers. We have found in a pilot study that students are reluctant to accept the constraints upon social behavior imposed by tasks of this sort. Therefore, like many of the earlier studies of TOD, we have had recourse to military personnel.

The prediction is that the EEG will fluctuate systematically with TOD and that main TOD effects will interact with personality (extroversionintroversion).

\section{SUBJECTS}

Ss were 20 male Junior Soldiers in their 8th month of training, with an average age of 17 years 2 months. These Ss had regular meals at 0645 , 1245 , and $1730 \mathrm{~h}$, arose daily at 0630 , and were obliged to retire at 2300 . During training they were subjected to approximately equal daily amounts of academic work, military training, and physical activity. Each $S$ received an attendance fee of $50 \mathrm{p}$.

\section{PROCEDURE}

Times of Attendance

Ss were divided into two groups of 12 and 8 , attending on 2 weeks of testing. Times of attendance were 0700-0815, 1000-1130, 1500-1645, and $1945-2115 \mathrm{~h}$. Ss attended in subgroups of three or four. The subgroups were allocated to four visits over 3 days, with random order of attendance and the constraint that no two subgroups followed the same sequence of TOD visits. Times of attendance were inserted within the normal working day, and Ss were extracted from and returned to their existing work schedules.

Physical Arrangements

The $S$ sat in an adjustable hairdresser's chair in the center of a soundproofed booth $(6 \times 8 \mathrm{ft})$. The booth was in the corner of a carpeted laboratory $(24 \times 20 \mathrm{ft})$ with double-glazed windows and blackout blinds. The outer room was kept at a constant level of illumination for all TOD. The door of the booth was kept open to enable constant monitoring of the S's eyes. Illumination to the booth was provided by diffuse light through the open door and frosted window to the rear of the $\mathbf{S}$; no shadows were cast in the booth and the ambient lighting level was below $1 \mathrm{~lm}$. The S could hear the hum of the booth air extractor fan and the regular sound of a data punch. Experimental Schedule and Instructions

Instructions were given at each session by an $\mathrm{E}$ who sat at the open door of the booth. The Ss were instructed to relax, not to think of anything, nor to mark the passage of time or count. They were to open and shut their eyes upon instruction and, in the eyes-open condition, to fixate upon a white dot ( $3 / 8 \mathrm{in}$. in diam) set in the center of a matte-black horizontal rectahgle set upon a wall $3 \mathrm{ft}$ in front of them. At each testing session, the height of the chair was adjusted until the S's angle of regard was at 90 deg to the dot. After a 2-min pretrial resting period, there were five alternating eyes-closed, eyes-open trials (three closed, two open), each of 
2-min duration. Total testing time was $12 \mathrm{~min}$.

The EEG was recorded from silver/silver chloride pad electrodes, presoaked in a $5 \%$ saline solution and held on by a rubber net. Electrodes were placed transoccipitally for bipolar recording (Cooper, Osselton, \& Shaw, 1969), with the reference electrode on the nonpreferred wrist. Each $S$ had a personal string marking net in the shape of a letter "T." After fixing the rubber electrode retaining net on the first session, the foot of the $T$ was cut to reach the tip of the S's nose, and the arms of the $T$ held at right angles to reach the upper tip of the S's ears, with the junction at the midline. The electrodes were placed beneath marks set at 2 in. on either side of the junction, and the same marking net was used for the same $S$ on all testing sessions. Interelectrode resistance ranged between 1 and 7 kilohms, with a mean value of 4.1 kilohms. The primary record was provided by a San'ei P.G. 802 polygraph, calibrated before each individual recording to give a $20-\mathrm{mm}$ peak to trough for 100 microvolts, with a time constant of $0.3 \mathrm{sec}$. Low-frequency analysis was provided by a San'ei E.A. 201 analyzer, equipped with the following purpose-built pure bandpass filters: $4.5-6.5 \mathrm{~Hz}$ and $7.5-13.5 \mathrm{~Hz}$ (in six single-cycle steps). These filters are steep skirted and flat topped; before each experimental run, the filters were tested for linearity with sine wave oscillators set at the midpoint for each filter. The analyzer was set at a 5 -sec epoch time. The integrated outputs of the filters were converted to digital form by a Lion Systems Development A-D converter and punched in a six-hole binary code on paper tape. These values were subsequently reproduced in decimal form on computer lineprint. The primary EEG record was monitored on a continuous paper writeout.

EEG Data Reduction

For each 2-min trial, there were $24 \times 5$ sec epoch values for each of the seven frequency filters. The 20 central values were summed and averaged for each trial for each $S$. These filter values were then collapsed separately to give three sets of scores: (1) the first eyes-closed trial (Trial 1), (2) the second and third eyes-closed trials (Trials 2 and 4 ), and (3) the two eyes-open trials (Trials 3 and 5 ).

Personality Inventory

The Eysenck Personality Inventory (Eysenck \& Eysenck, 1964) was administered after completion of the final visit.

\section{RESULTS}

Times of Day: EEG Abundance

Friedman analyses of variance by
Table 1

Rank Correlations for the Four Times of- Attend ance

\begin{tabular}{|c|c|c|c|c|}
\hline & 0700 & 1000 & 1500 & 2000 \\
\hline & Eyes & Closed: & $8.5 .13 .5 \mathrm{~Hz}$ & \\
\hline $\begin{array}{l}0700 \\
1000 \\
1500\end{array}$ & & $0.76 t$ & $\begin{array}{l}0.47^{*} \\
0.53^{* *}\end{array}$ & $\begin{array}{l}0.85+ \\
0.66 t \\
0.54 * *\end{array}$ \\
\hline
\end{tabular}

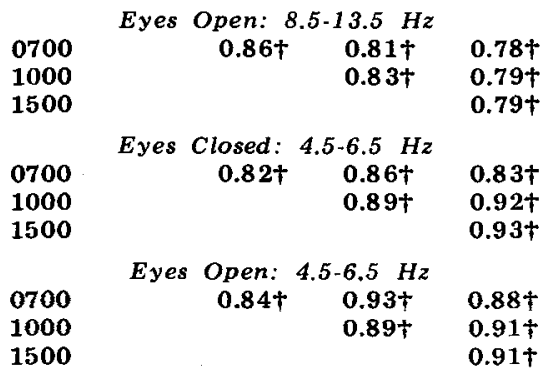

Note-df $=18$

tp $<.01$, two-tailed

$* * p<.05$, two-tailed

${ }^{*} p<.025$, one-tailed

ranks (Siegel, 1956) were computed for $4.5-6.5 \mathrm{~Hz}$ (theta), for each of the six individual filters $(7.5-13.5 \mathrm{~Hz}$, alpha range), and for $7.5-13.5 \mathrm{~Hz}$ collapsed (alpha total), comparing scores for the four TOD and taking Trial 1, eyes-closed trials, and eyes-open trials separately. None of the tests reached significance, nor did paired-comparison tests comparing a.m. and p.m. scores collapsed.

Times of Day: EEG Frequency

Inspection of the frequency distributions of activity within alpha range for the different TOD indicated that further analyses designed to detect a shift in dominant frequency within this range was unjustified.

EEG Abundance and Personality

The extroversion scores ranged from 4 to 20 , with a mean of 14.1 and a SD of 3.1. Product-moment correlations were computed between extroversion (E) and neuroticism (N) scores and alpha total and theta for eyes-open and eyes-closed trials for the four TOD and the first visit (i.e., independent of time of attendance). Of the 34 correlations thus computed, only one reached significance at the $5 \%$ level (extroversion-alpha total at 0700 , $r=-0.38$ )

\section{Session to Session Variation}

A sign test (Siegel, 1956) comparison of first and final visit (independent of time of attendance) showed alpha total for eyes closed to be significantly lower on the final occasion ( $\mathrm{p}<.05$, one-tailed). A product-moment correlation was computed between $\mathrm{E}$ and the ratio of maximum and minimum alpha totals over the four visits. $\mathrm{E}$ was directly related to range of variation (alpha total-eyes closed, $r=0.414, p<.05$; eyes open, $r=0.476, \quad p<.025$ ). Neither the maximum nor minimum scores were related to either a particular TOD or a particular visit.

Test-Retest Reliability of the EEG

Spearman rank correlations (Siegel, 1956) were computed for alpha total and theta between the different TOD. These were all significant, for both frequency ranges and for both eyes-open and eyes-closed trials (see Table 1).

The main prediction of this study that TOD will have systematic effects upon the EEG, has not been supported; nor is there any systematic variation attributable to personality or to an interaction between personality and TOD. The task employed was a simple one, calling for little effort on the S's part. However, many of the previous tasks demonstrating TOD effects have been relatively undemanding. But even for a relatively difficult task, involving continuous monitoring of sensory input, TOD effects may fail to occur (Gale et al, in press). It would appear that TOD effects are delicate plants which flourish only under certain critical conditions.

Gale et al (1969) obtained higher EEG abundance for extroverts employing an identical task; however, in the present study the Ss were informed from the outset that the procedure for all attendances would be identical and were, therefore, aware of the unrelieved monotony presented by the task. It is typically those tasks which are monotonous and provide inadequate stimulation for extroverted Ss that are least likely to yield differences for $\mathrm{E}$ and the EEG. Many of the equivocal findings for the EEG/extroversion relationship may be interpreted in terms of the demand characteristics of experimental instruction. When tasks are tedious (i.e., "resting" conditions or habituation studies), the $\mathbf{S}$, particularly the extrovert, is obliged to engage in self-stimulation (i.e., mental activity) to sustain wakefulness (Gale et al, in press). Extroverts report greater vividness of imagery than introverts (Gale et al, in press; Morris $\& \mathrm{Gale}^{1}$ ), and the act of imaging does lead to alpha suppression (Gale et al, in press). The reduction in alpha abundance for eyes closed between the first and final visit supports the inference that $S s$, being deprived of stimulation, were arousing themselves by mentation. The finding that session to session variability is directly related to extroversion supports the notion that extroverts show more intrapersonal variability in behavior than introverts (Eysenck, 1947; Spielman, 1963; Gale, 1969). So far as we are aware, this is the first occasion upon which repeated measures have 
been taken on separate visits rather than within one experimental session.

The set of extremely high rank correlations in Table 1 indicates that the EEG is a reliable measure of individual differences and that the source of such variation is powerful enough to mask any possible TOD effects. Again, so far as we are aware, no previous study has employed repeated measures on four separate occasions. One determinant of the unusual magnitude of the correlations is the range of scores; for example, at the 1000-h session alpha total for eyes closed ranges between $S$ means for a 4-min sample of 10.91 to 40.01 arbitrary units of abundance. Thus, although an individual may vary considerably from session to session, there may be little overlap in score with adjacently ranked Ss. The stability of $\mathrm{S}$ scores indicates that failure to obtain TOD effects is not merely the result of measurement error. The findings for TOD could have been attributable to a wholly random distribution of dependent variable scores, but the test-retest reliability is evidence of systematic variation. These striking correlations are encouraging for the worker in this field, first because they demonstrate the test-retest reliability of the EEG, second because they demonstrate the value of measuring theta activity as well as the more popular alpha, and finally because time of experimental session may not constitute a significant source of error variance in EEG studies of individual differences. Thus Es have many more degrees of freedom in the allocation of Ss to experimental times. Nevertheless, this result has been arrived at inadvertently, and a replication study is therefore called for.

\section{REFERENCES}

BLAKE, M. J. F. Relationship between circadian rhythm of body temperature and introversion-extraversion. Nature, 1967, 215, 896-897.

COOPER, R., OSSELTON. J. W., \& SHAW, J. C. EEG technology. London: Butterworth, 1969.

COLQUHOUN, W. P. Temperament, inspection efficiency, and time of day. Ergonomics, 1960, 3, 377-378.

COLQUHOUN, W. P., \& CORCORAN, D. W. J. The effects of time of day and social isolation on the relationship between temperament and performance. British Journal of Social \& Clinical Psychology, 1964, 3, 226-231.

DAVIES, D. R., \& TUNE, G. S. Human vigilance performance. London: Staples Press, 1970.

EYSENCK, H. J. Dimensions of personality. London: Routledge \& Kegan Paul, 1947.

EYSENCK, H. J., \& EYSENCK, S. B. G. Eysenck personality inventory. London: University of London Press, 1964.

GALE, A. The psychophysiology of individual differences. In P. Kline (Ed.) New approaches in psychological measurement. London: Wiley, in press.

GALE, A. Stimulus hunger: Individual differences in operant strategy in a button-pressing task. Behaviour Research \& Therapy, 1969, 7, 265-274.

GALE, A., BULL, R., PENFOLD, V.,
COLES, M., \& BARRACLOUGH, R. Extroversion, time of day, vigilance performance, and physiological arousal: Failure to replicate traditional findings. Psychonomic Science, in press.

GALE, A., CHRISTIE, B., \& PENFOLD, V. Stimulus complexity and the occipital EEG. British Journal of Psychology, $1971,62,527-531$.

GALE, A., COLES, M., \& BLAYDON, J. Extraversion-introversion and the EEG. British Journal of Psychology, 1969,60. 209-223.

GALE, A., HASLUM, M., \& PENFOLD, V. EEG correlates of cumulative expectancy and subjective estimates of alertness in a vigilance-ty pe task. Quarterly Journal of Experimental Psychology, 1971, 23, 245-254.

GALE, A., MORRIS, P. E., LUCAS, B., \& RICHARDSON, A. Types of imagery and imagery types: An EEG study. British Journal of Psychology, in press.

KLEITMAN, $N$, Diurnal variation in performance. American Journal of Physiology, 1933, 104, 449-456.

LINDSLEY, D. B. Attention, consciousness, sleep and wakefulness. In J. Field, H. W. Magoun, and V. E. Hall (Eds.). Handbook of physiology: Neurophysiology, III. Washington, D.C: American Physiological Society, 1960. Pp. 1553-1593.

OSWALD, I. Sleeping and waking. Amsterdam: Elsevier, 1962.

SIEGEL, S. Nonparametric statistics. New York: McGraw-Hill, 1956.

SPIELMAN, J. The relation between personality and the frequency and duration of involuntary rest pause during massed practice. $\mathrm{Ph} . \mathrm{D}$. thesis, University of London, 1963.

\section{NOTE}

1. Morris, P E \& Gale, A Some correlations between measures of imaging ability, incidental recall, personality, and EEG. In preparation. 